Atmos. Chem. Phys., 10, 4597-4609, 2010

www.atmos-chem-phys.net/10/4597/2010/

doi:10.5194/acp-10-4597-2010

(C) Author(s) 2010. CC Attribution 3.0 License.

\title{
On the roles of circulation and aerosols in the decline of mist and dense fog in Europe over the last 30 years
}

\author{
G. J. van Oldenborgh ${ }^{1}$, P. Yiou ${ }^{2}$, and R. Vautard ${ }^{2}$ \\ ${ }^{1}$ KNMI, P. O. Box 201, 3730 AE De Bilt, The Netherlands \\ ${ }^{2}$ LSCE/IPSL, Laboratoire CEA/CNRS/UVSQ, 91191 Gif-sur-Yvette Cedex, France
}

Received: 23 October 2009 - Published in Atmos. Chem. Phys. Discuss.: 12 November 2009

Revised: 26 April 2010 - Accepted: 7 May 2010 - Published: 19 May 2010

\begin{abstract}
Fog and mist are meteorological phenomena that have significant contributions to temperature variations. Understanding and predicting them is also crucial for transportation risk management. It has been shown that low visibility phenomena over Europe have been declining over the past three decades. The trends in mist and haze have been correlated to atmospheric aerosol trends. However, dense fog has not received yet such focus. The goal of this paper is to examine the roles of synoptic atmospheric circulation and aerosol content on the trends of dense fog. We show that sulphur emission trends are spatially correlated with visibility trends, with a maximum correlation when visibility is between $1 \mathrm{~km}$ and $10 \mathrm{~km}$. We find that atmospheric dynamics overall contributes up to $40 \%$ of the variability of the frequency of fog occurrences. This contribution is spatially variable and highly depends on the topography and the season, with higher values in the winter. The observed long-term circulation changes do not contribute much to the trends in low visibility found in the data. This process is illustrated on three stations (De Bilt, Zürich Airport and Potsdam) for which a long-term visibility data and a thorough meteorological description are available. We conclude that to properly represent fog in future climate simulations, it is necessary to include realistic representations of aerosol emissions and chemistry, land surface properties and atmospheric dynamics.
\end{abstract}

Correspondence to:

G. J. van Oldenborgh

(oldenborgh@knmi.nl)

\section{Introduction}

Fog and mist are meteorological phenomena with a large societal impact. They strongly affect the surface temperature by reflecting sunlight and isolating the ground from atmospheric layers above the fog. More directly, low visibility also impacts all forms of traffic. Understanding the characteristics of those phenomena is hence an important societal issue. However, these low visibility phenomena are poorly predicted by numerical weather forecast models and cannot be adequately represented in climate models yet. This affects the temperature simulations of these models. The poor simulation of fog and mist in climate models also implies that these phenomena are usually not included in climate change scenarios, in spite of their importance to society.

In a previous paper we showed that a strong decline of the number of mist and fog days has been observed in Europe over the period 1976-2006 (Vautard et al., 2009), using a multidecadal global visibility archive. The decline in European air pollution was shown to be linked to the visibility increase: the temporal and spatial patterns of fog and mist declines are strongly correlated with emission reductions. We showed that the reduction in low visibility phenomena in $\mathrm{Eu}-$ rope contributed 10 to $20 \%$ to the day-time temperature trend 1976-2006, reaching 50\% in parts of eastern Europe. However most of the effect was found to be due to visibilities ranging from 1 to $5 \mathrm{~km}$. Dense fog, with visibilities less than a few tens or hundreds of meters was not studied in detail. More generally, many studies have quantified the radiative effects of changes in aerosol loads (see e.g. Wild, 2009, for a review), but changes in dense fog are poorly documented.

Published by Copernicus Publications on behalf of the European Geosciences Union. 
In this paper we first extend the trend analysis to dense fog (less than $200 \mathrm{~m}$ visibility). We group all causes of low visibility and do not distinguish between different mechanisms (e.g. radiation fog, advection fog, stratus lowering, aerosol haze), but exclude mountain stations where low visibility is mainly due to clouds.

Next we perform a statistical analysis of two factors that are likely candidates for explaining the trend in low visibility: aerosols and atmospheric circulation. These factors are used in meteorological fog forecasting systems.

For aerosols we compare the spatial and temporal patterns of the trend in low visibility with the patterns of $\mathrm{SO}_{2}$ emission trends in Europe. The results are very similar when we use $\mathrm{NO}_{\mathrm{x}}$ emissions, as the trends in these are strongly correlated over the period considered. The statistical analysis therefore does not enable us to study the different effects of different types of aerosols. We do consider the possible effects of changes in urbanisation using the same spatial comparison technique.

The atmospheric circulation is first investigated using the daily pressure field. We consider the daily large-scale weather patterns affecting fog and mist occurrences at three stations for winter (October-March) and summer (AprilSeptember). This reveals which daily circulation types lead on average to low visibility at these stations. Next we compare these daily circulation patterns to the seasonal mean patterns associated with anomalously large number of fog or mist days in that season (relative to the trend). The most important features of these seasonal sea-level pressure (SLP) patterns turn out to be the local gradients at the station where the low visibility has been recorded. These gradients (the geostrophic wind) are used as a concise description of the large-scale circulation to investigate its effect on the number of low visibility occurrences at all stations.

There are two pathways in which atmospheric circulation influences fog. The first is direct: certain large-scale circulation types are more likely to give rise to the micrometeorological conditions that are conducive for radiation or advection fog formation (for radiation fog: no clouds, a low wind speed and a stably stratified atmosphere near the ground). The second pathway is indirect, by affecting aerosol concentrations at ground level for given emissions. The large-scale circulation influences advection of pollution from the emission points to other regions, the height of the mixed layer and the probability of precipitation that removes aerosols from the air.

The relationships that we find between fog and mist and the two factors aerosols and atmospheric circulation allow us to make qualitative projections of the future number of fog and mist days that follow from a range of emission and circulation scenarios.

\section{Data}

Horizontal-visibility data have been taken from the 6-hourly NCEP ADP land surface observations available at the National Centre for Atmospheric Research (NCAR) server http: //dss.ucar.edu/datasets/ds464.0. We selected 329 European stations (out of 4479 ) within $\left[10^{\circ} \mathrm{W}-30^{\circ} \mathrm{E} ; 35^{\circ} \mathrm{N}-60^{\circ} \mathrm{N}\right]$. Stations were selected that had data over at least 1980-2000, at least 10 years with at least two observations per day, and at least 30 observations in all half-year seasons between 1980 and 2000 (excluding 1997). The details of the selection procedure are given in Vautard et al. (2009). Compared to that list, we excluded 9 high-altitude stations (above $1000 \mathrm{~m}$ ). Six stations showed very obvious breaks in a visual inspection of the time series: 02566 Krokshult SE; 03495 Coltishall UK, 03827 Plymouth/Mount Batt. UK, 06260 De Bilt NL, 06344 Rotterdam Airport NL and 11406 Cheb CZ. For the Dutch stations the break coincides with the introduction of automatic weather stations in 2001 . We consequently left out the years 2002-2006 for all Dutch data. The other four stations were removed from the dataset.

About two-thirds of the stations correspond to airports or airfields, at which low visibility observations are very important and often performed with more care (J. van der Meulen, personal communication, 2008). When plotting the results separately for airports/airfields and other stations it is apparent that the latter subset indeed contains more noise (not shown). However, there do not appear to be other systematic differences between the two subsets. In the following we present results for the complete dataset.

To keep the number of figures manageable we show results mainly for visibility less than $200 \mathrm{~m}$ (dense fog) and $2 \mathrm{~km}$ (an air traffic threshold). The same plots for intermediate values and higher can be obtained from the authors. Not enough stations report $50 \mathrm{~m}$ visibilities to do the analyses for this threshold, and the results for $100 \mathrm{~m}$ are also less complete.

We also use longer time series of daily minimum visibility observed at De Bilt 1955-2001 (available from the KNMI web site), Zürich Airport (courtesy of MeteoSwiss) and Potsdam (courtesy of Deutsche Wetterdienst).

Circulation indices are derived from the NCEP/NCAR Reanalysis-1 (Kalnay et al., 1996) sea-level pressure field (SLP).

Historical sulphur dioxide emissions 1990-2007 were obtained from the European Monitoring and Evaluation Programme (EMEP) web site at $0.5^{\circ}$, and averaged into $2.5^{\circ}$ grid boxes. For the future emission scenarios we used the three Representative Concentration Pathways (RCPs, the emission scenarios for the Fifth Coupled Model Intercomparison Project CMIP5 and the fifth IPCC assessment report) for which data were available at the time of writing: RCP26 (van Vuuren et al., 2007), RCP45 (Smith and Wigley, 2006; Wise et al., 2009) and RCP85 (Riahi et al., 2007). Historical land 
use data up to 2005 on a $0.5^{\circ}$ grid have also been obtained via the CMIP5 site and are described in Hurtt et al. (2006).

\section{Mean and trends in dense fog and mist}

We first extend the trend analysis of Vautard et al. (2009) to dense fog. In that paper trends were only established for horizontal visibilities cut-offs of $1 \mathrm{~km}$ and higher. These have the largest effects on temperature, due to the more frequent occurrence. However, dense fog (visibility less than $200 \mathrm{~m}$ ) is also very important for traffic safety. Very dense fog (visibility less than $50 \mathrm{~m}$ ) is not reported by all stations, and could therefore not be analysed. A downward trend in dense fog in the Netherlands was already noted by Knip (2002).

In this analysis we concentrate on the daily minimum visibility. For the NCAR dataset this is defined as the minimum of the 00:00, 06:00, 12:00 and 18:00 UTC observations. In contrast, Vautard et al. (2009) considered the daily mean, day-time and night-time visibility, which are more relevant for temperature effects. The mean number of days per half year with minimum visibility less than $200 \mathrm{~m}$ and $2 \mathrm{~km}$ is shown Fig. 1. The numbers are very low on the Mediterranean coasts, in Ireland and on the west coast of Great Britain. Eastern Europe and the Alps have the highest numbers of fog and mist days.

Figure 2 shows the relative decline in fog and mist days in Europe in winter (October-March) and summer (AprilSeptember) 1976-2006, based on the NCAR dataset. The relative decline is defined with respect to the mean number of days over the whole period, not relative to the number of days at the beginning of the period. A value of $5.5 \% \mathrm{yr}^{-1}$ indicates a total elimination of fog or mist, from twice the mean value to nothing over 31 years, $3 \% \mathrm{yr}^{-1}$ means the number of days has halved.

We computed $p$-values of the linear trend fit using a standard two-sided $t$-test. The negative trends in $2 \mathrm{~km}$ visibility are significant at $p<0.1$ for around two-thirds of the stations, decreasing to half the stations at $p<0.01$, see Table 1 . The fraction of stations with positive trends is comparable to the fraction expected by chance in data with no trend, $p / 2$, but the fraction of stations with negative trends is much larger. The non-significant trends are located mainly in North Africa, southern Spain and western Scotland and Ireland. In these regions fog is rare and the trends mainly due to random fluctuations of the weather in a small sample.

For dense fog (visibility less than $200 \mathrm{~m}$ ) the variability is much larger. On average the relative trends are very similar to the trends of $2 \mathrm{~km}$ visibility, but the scatter around the mean value is much larger. This is also apparent in the significances: only one third of the stations have a negative trend that is statistically significant at $p<0.1$, and one out of six a negative trend with $p<0.01$. Again the fraction of positive trends is comparable to the fraction expected by chance.
We conclude that in Europe there is a significant downward trend in the observations of dense fog. The relative trends in days with dense fog are comparable to the trends in days with less extreme low visibility, albeit with more scatter around the mean value.

\section{Correlations with sulphur emissions}

Two factors that are taken into account when considering the spatial distribution of fog in weather forecasts are aerosols and land use (e.g. Musk, 1991). Aerosols provide condensation nuclei for fog formation, and at longer visibilities also intercept the light themselves. Urbanisation affects the nighttime surface temperatures, roughness and moisture availability. There is less cooling in the less open terrain of a city, the high roughness implies a boundary layer that is too thick for fog to form, and less evaporation may mean less moisture availability for fog.

Concerning aerosols, Vautard et al. (2009) have shown that the spatial pattern of daily mean $5 \mathrm{~km}$ visibility trends 1976 2006 was highly correlated with EMEP emission trends 1990-2000. There is evidence that air pollution also affects dense fog. Observations during a fog episode in polluted air during the ParisFog field campaign (Elias et al., 2009) indicated that hydrated aerosols dominated light extinction in haze (visibility $400-800 \mathrm{~m}$ to $5 \mathrm{~km}$, humidity $90 \%-100 \%$ ). During the fog hours (visibility less than $400-800 \mathrm{~m}$, humidity $100 \%$ ) these particles also contributed, although the larger water droplets cause a stronger extinction. Rangognio et al. (2009) show in a modelling study of one of these fog episodes that the fog properties depend critically and nonlinearly on the aerosol concentrations and properties. Moderately polluted air leads to more droplets and higher liquid water concentration (LWC), but in heavily polluted air both the droplet numbers and LWC drop again. In earlier micrometeorological modelling studies of fog Bott (1991) and von Glasow and Bott (1999) already found that urban aerosols cause higher water content and longer-lasting fog than rural aerosols, supporting the finding that fog properties are strongly influenced by aerosols.

In Fig. 3 we extend the analysis of Vautard et al. (2009) to lower visibilities: a comparison of the pattern of visibility trends on a map of Europe with the pattern of $\mathrm{SO}_{2}$ emission trends. For a range of cut-offs from $100 \mathrm{~m}$ to $10 \mathrm{~km}$ we computed the spatial rank correlation between the trend in the number of days with minimum visibility less than the cut-off and the EMEP $\mathrm{SO}_{2}$ emission trends over 1990-2007 (Streets et al., 2006). The two data points before 1990 in the emission dataset have large uncertainties and have been omitted. The visibility trends have been computed on the same $2.5^{\circ} \times 2.5^{\circ}$ grid as the emission data, covering $10^{\circ} \mathrm{W}-35^{\circ} \mathrm{E}, 37^{\circ}-60^{\circ} \mathrm{N}$, demanding at least two stations in each grid box. The grid box value was computed as the average of the trends of the stations, weighted with the inverse square of the error on the 

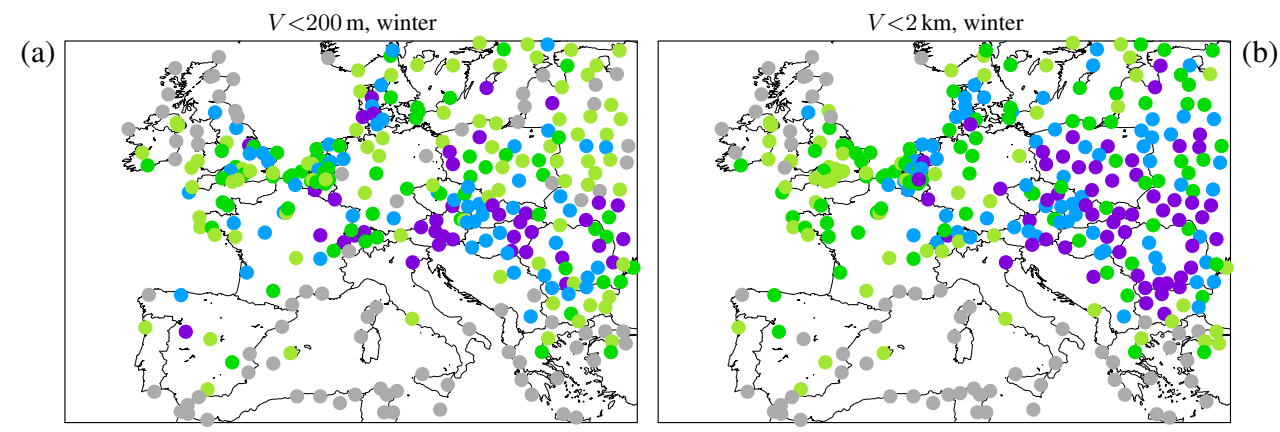

(c)
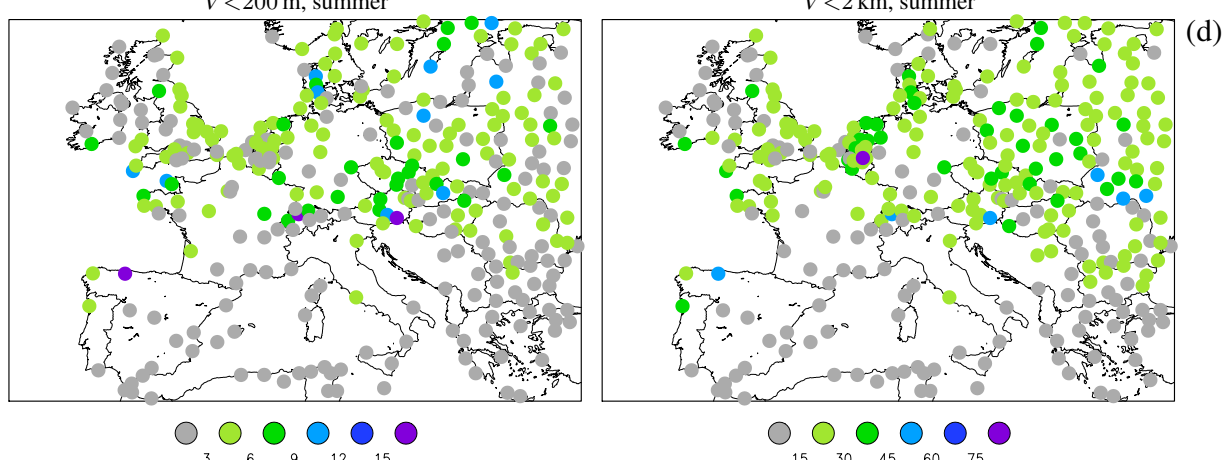

Fig. 1. Mean number of days per half year with low visibility over 1976-2006 in winter (a) and (b) October-March, and summer (c) and (d) April-September. In (a) and (c) the number of days with dense fog (visibility less than $200 \mathrm{~m}$ ) is shown, in (b) and (d) the number of days with visibility less than $2 \mathrm{~km}$.

(a)

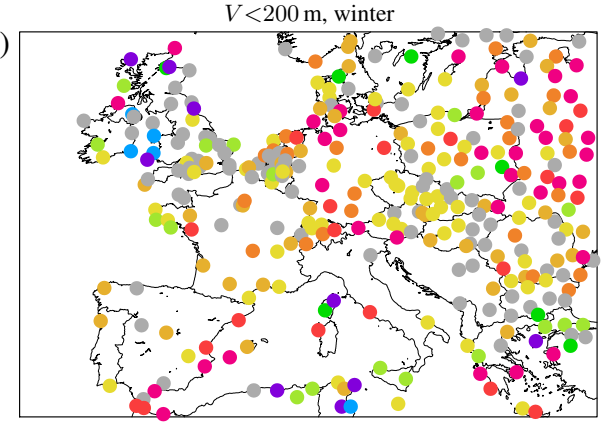

(c)

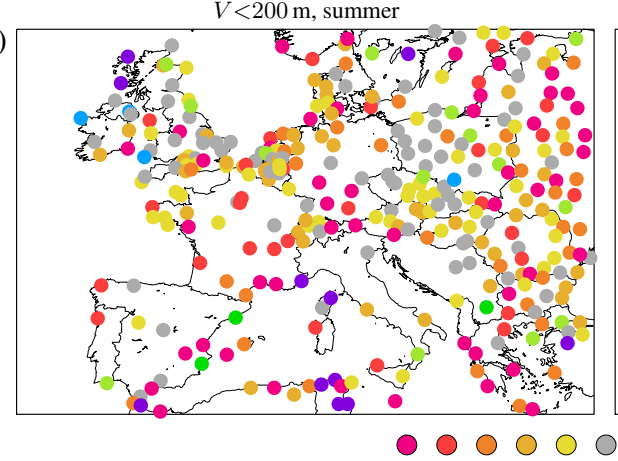

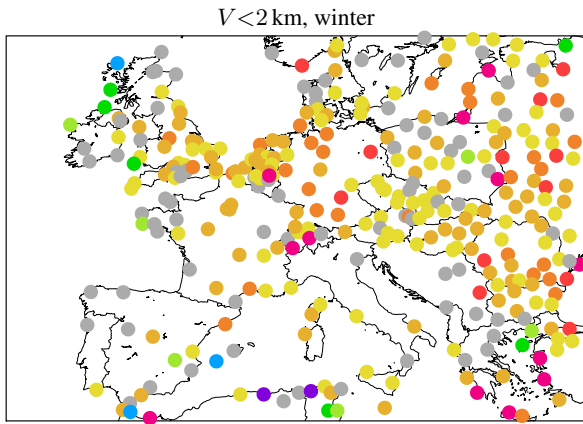

(b)

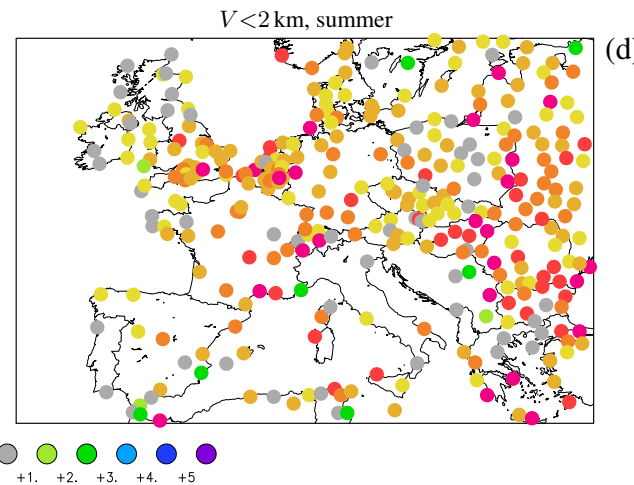

Fig. 2. Relative trend in low visibility [\%/yr] over 1976-2006 in winter (a) and (b) October-March, and summer (c) and (d) April-September. In (a) and (c) the number of days with dense fog (visibility less than $200 \mathrm{~m}$ ) is shown, in (b) and (d) the number of days with visibility less than $2 \mathrm{~km}$. 
Table 1. Fraction of the 329 stations with positive/negative trends in days with low visibility that are significant at the $p$-values in the first column.

\begin{tabular}{lcccc}
\hline$p$ & \multicolumn{2}{c}{ winter } & \multicolumn{2}{c}{ summer } \\
& $V<200 \mathrm{~m}$ & $V<2 \mathrm{~km}$ & $V<200 \mathrm{~m}$ & $V<2 \mathrm{~km}$ \\
\hline 1.0 & $0.21 / 0.79$ & $0.12 / 0.88$ & $0.18 / 0.82$ & $0.07 / 0.93$ \\
0.1 & $0.04 / 0.37$ & $0.03 / 0.64$ & $0.03 / 0.36$ & $0.02 / 0.75$ \\
0.05 & $0.03 / 0.29$ & $0.02 / 0.59$ & $0.02 / 0.29$ & $0.01 / 0.71$ \\
0.01 & $0.01 / 0.17$ & $0.01 / 0.46$ & $0.02 / 0.17$ & $0.01 / 0.54$ \\
0.005 & $0.00 / 0.14$ & $0.01 / 0.43$ & $0.01 / 0.13$ & $0.00 / 0.49$ \\
0.001 & $0.00 / 0.09$ & $0.00 / 0.30$ & $0.01 / 0.06$ & $0.00 / 0.38$ \\
\hline
\end{tabular}

trend (from the fitting procedure). Finally, a rank correlation was chosen as we can only assume a monotonic decrease of visibility with aerosol concentrations at most sites in Europe, not a linear decrease.

To compute the significance of the correlations, the spatial autocorrelation has to be taken into account: the 88 grid boxes with data are not all independent. A spatial autocorrelation function was computed from all pairs of grid boxes. From this graph the decorrelation scale was estimated to be $4^{\circ}$ for the trend in the number of days with visibility smaller than $2 \mathrm{~km}$ to $2^{\circ}$ for $200 \mathrm{~m}$ (Sterl et al., 2007). This gives rise to estimates of 50 degrees of freedom for $2 \mathrm{~km}$, to 88 for $200 \mathrm{~m}$. The corresponding one-sided confidence levels at $p<0.05$ are indicated by the green line.

The figure shows a positive spatial rank correlation between emission trends and low visibility trends at all distances. All correlations are significant at $p<0.05$. The strength of the correlation decreases for low visibilities (the higher value for $100 \mathrm{~m}$ may well be a coincidence as fewer stations report this distance). This decrease is at least partly due to the much smaller spatial scales apparent in the trends for smaller cut-offs (compare Fig. 2a and 2b). These details are lost in the $2.5^{\circ} \times 2.5^{\circ}$ grid used for the comparison.

We also investigated the spatial correlation of low visibility trends with an estimate of the trends in urbanisation over 1976-2006. The fraction with urban land use on a $0.5^{\circ}$ grid 1976-2005 (Hurtt et al., 2006) has been been averaged to the same $2.5^{\circ}$ grid as the emission data. From the meteorological experience that fog occurs less frequently in builtup areas we expect that more urban land is associated with less fog and mist occurrences. The spatial correlations between urbanisation trends and low visibility occurrences are indeed negative for all ranges, although not all are significant at $p<0.05$ (one-sided). For easier comparison with the aerosol signal the sign of the correlation coefficients has been changed to positive in Fig. 3. The strengths of the spatial correlations seem lower than for $\mathrm{SO}_{2}$ emissions, although the difference is not statistically significant. The lower correlations are due to the largest trends to more urban land having occurred in western Europe, whereas the increase in air qual- rank correlation with annual absolute visibility trends

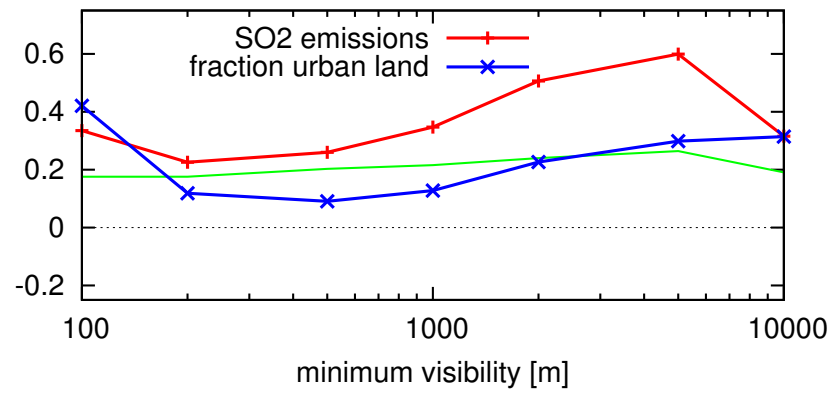

Fig. 3. Spatial rank correlation of the trend in the annual number of days with minimum visibility less than a range of cut-offs with the trend in EMEP SO 2 emissions 1990-2007 (Streets et al., 2006) and with the trend in the fraction of urban land (Hurtt et al., 2006) (with sign changed) on a $2.5^{\circ} \times 2.5^{\circ}$ grid covering $10^{\circ} \mathrm{W}-35^{\circ} \mathrm{E}, 37^{\circ}-$ $60^{\circ} \mathrm{N}$. The green line indicates the correlations that have $p=0.05$, using a number of degrees of freedom deduced from the spatial autocorrelation.

ity has also been very strong in eastern Europe. The latter pattern matches the fog trend signal better.

Another line of evidence for a significant influence of aerosols on fog formation, even at visibility threshold below $1 \mathrm{~km}$, comes from the temporal evolution at the stations for which long time series are available. Sulphur emissions in western Europe peaked between 1970 and 1980, in eastern Europe somewhat later (Stern, 2006). In Fig. 4 we show the annual number of dense fog and mist days in the long time series available at De Bilt (the Netherlands), Zürich Airport (Switzerland) and Potsdam (Germany). These stations all show that the number of fog and mist days start to decline quickly at some time between 1970 and 1985. Before this date there is no trend (De Bilt), a slower decrease (Zürich Airport) or an increase (Potsdam) in the number of fog or mist days.

We estimated the break-point from the $5 \mathrm{~km}$ visibility data to be 1985 for De Bilt, 1975 for Zürich Airport and Potsdam. The difference in trend before and after the break-point is always negative, and significant at $p<0.05$ (one-sided $t$-test) at all thresholds except $200 \mathrm{~m}$ at De Bilt, and $1 \mathrm{~km}$ in Zürich Airport. This behaviour can also be seen in other stations with long time series, but not when these are in heavily industrialised areas (e.g. Rotterdam, Saarbrücken): the number of fog days there shows a uniform decline.

The Hurtt et al. (2006) dataset shows almost uniform trends towards more urbanisation at coarse spatial scales at De Bilt and Zürich Airport, making the contribution from this land use change impossible to isolate with a temporal correlation technique (see e.g. Sies, 1988). At Potsdam there is a maximum around 1990, which probably reinforced the strong maximum in visibility seen in Fig. 4c. 
(a)

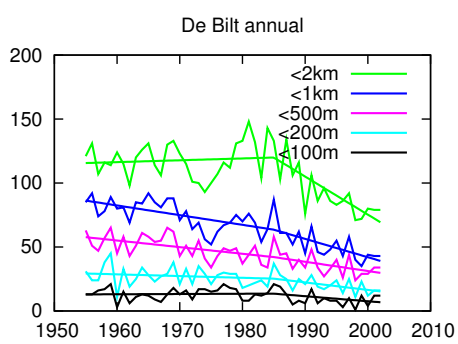

(b)

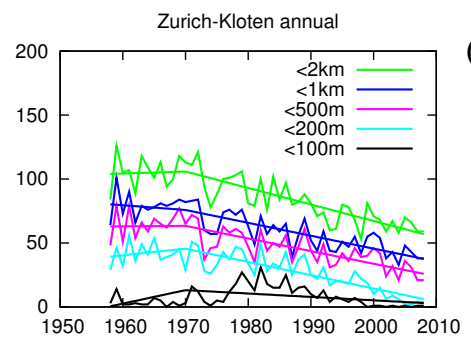

(c)

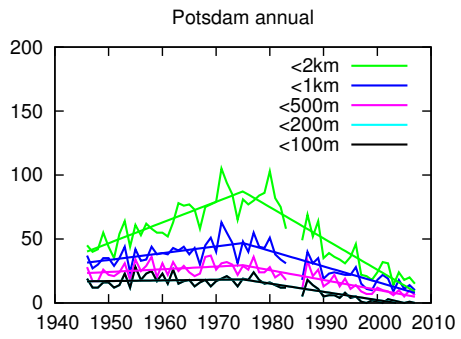

Fig. 4. The annual number of days with visibility less than $100 \mathrm{~m}, 200 \mathrm{~m}, 500 \mathrm{~m}, 1 \mathrm{~km}$ and $2 \mathrm{~km}$ at (a) De Bilt, (b) Zürich Airport and (c) Potsdam. The straight-line fits include a break-point estimated from the $5 \mathrm{~km}$ visibility.

It should be noted that the spatial and temporal correlations presented above are a first statistical analysis. The seasonal and small-scale spatial variability of sulphur emissions, which interact with the seasonal and small-scale spatial variability of fog, have not yet been taken into account. Neither have we considered the contribution of other emissions that lead to the formation of aerosols, such as black carbon and $\mathrm{NO}_{\mathrm{x}}$, although these are thought to be less easily activated into fog droplets (Rangognio et al., 2009).

We conclude that both from the large-scale spatial pattern of the trends in fog over the last decades and from the temporal patterns of longer time series, there is clear evidence that the improvement in air quality in Europe has contributed to the decrease in fog and mist days. As expected, the correlations are stronger for haze and mist ( $2 \mathrm{~km}$ and higher), but they are also statistically significant for (dense) fog. Given the large uncertainties of emissions before 1990 we have not been able to give a quantitative estimate of this contribution to the trend.

\section{Circulation patterns associated with low visibility at De Bilt, Zürich Airport and Potsdam}

\subsection{Daily SLP patterns associated with low visibility}

We investigate the weather types associated with dense fog and mist for the stations for which long time series are available, De Bilt, Zürich Airport and Potsdam. The daily SLP anomaly patterns are constructed as composites of SLP anomalies on the days at which a minimum visibility of less than $200 \mathrm{~m}(2 \mathrm{~km})$ was recorded. For reference the average SLP field 1949-2009 in summer and winter is shown in Fig. 5.

The deviations from climatology on days with low visibility are shown in Figs. 6 and 7. The patterns are different between summer and winter. However, the patterns associated with dense fog are similar to those associated with $2 \mathrm{~km}$ mist.

At De Bilt in winter, an anomalous easterly flow and high pressure are favourable to mist and fog formation. The pressure gradients of the anomalies cancel the climatological

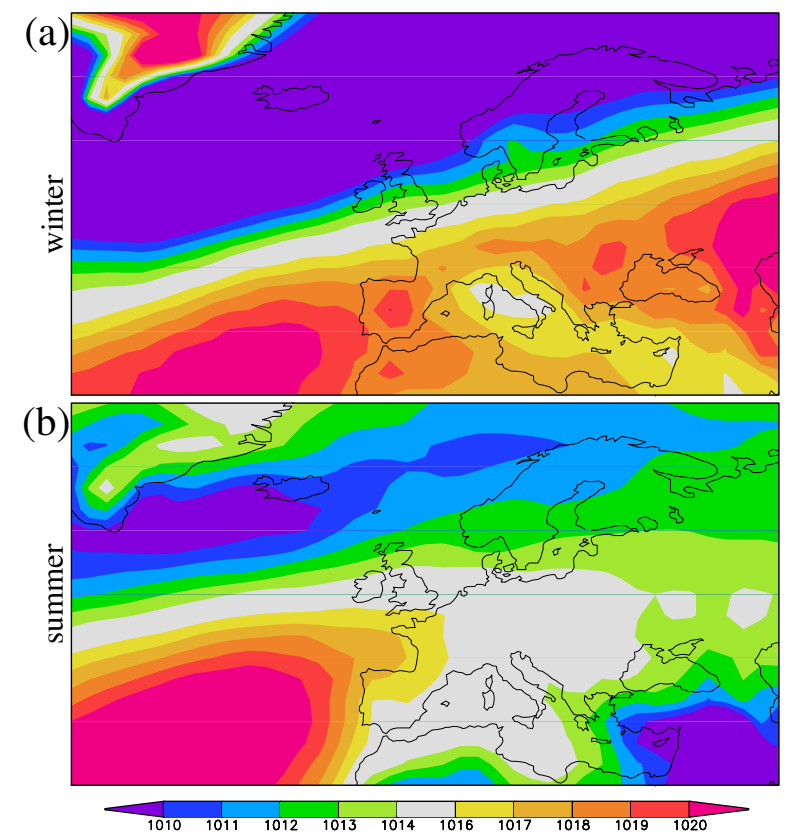

Fig. 5. Climatology of mean sea-level pressure anomalies $[\mathrm{hPa}]$ in winter (a) October-March, and summer (b) April-September.

gradients, creating conditions favourable for the low wind speeds and low temperatures that allow fog to form. Under a high pressure system there are usually fewer clouds, the atmosphere is more stably stratified and radiative cooling is more likely.

However, the same weather patterns also increase the concentrations of aerosols in the boundary layer. Westerly winds advect relatively clean maritime air to the Netherlands. In blocking or anticyclonic situations, polluted continental air is advected or even recirculated toward Western Europe allowing the build-up of high concentration loads (Vautard et al., 2005; Stern et al., 2008). In such conditions, a stably stratified atmosphere is generally found, with a thinner boundary layer, also increasing the aerosol burden near the surface.

In summer, dense fog at De Bilt is much rarer. The blocking high is on average considerably weaker and a bit more easterly than in the winter, but otherwise the same factors 


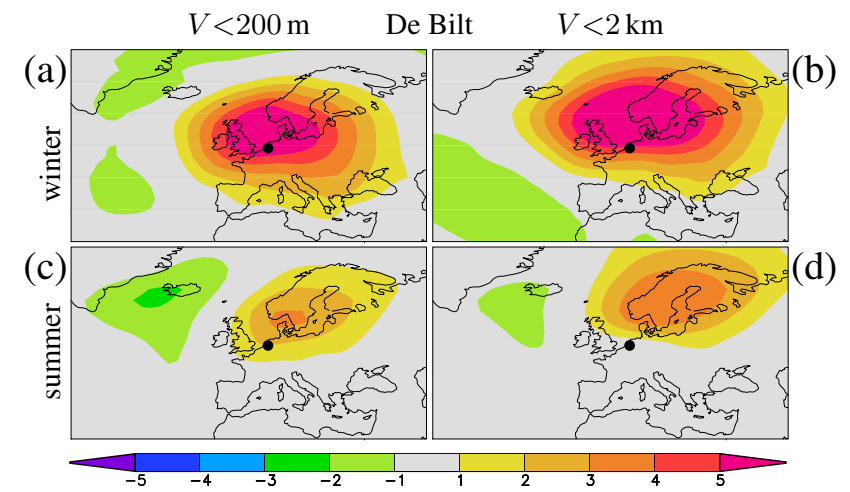

Fig. 6. Composite of daily mean sea-level pressure anomalies $[\mathrm{hPa}]$ at days with low visibility in De Bilt, the Netherlands (dot) in winter (a) and (b) October-March, and summer (c) and (d) AprilSeptember. In (a) and (c) SLP anomalies at days with dense fog (visibility less than $200 \mathrm{~m}$ ) is shown, in (b) and (d) at days with visibility less than $2 \mathrm{~km}$.

hold: the anomalous SLP gradients cancel the climatological gradients at the station where the observations are made and the pressure is higher than normal there.

At Zürich Airport winter fog is associated with a southerly anomalous geostrophic flow at the surface (the derivative of the SLP field) across the Alps: south-westerly in winter, south-easterly in summer (Fig. 7). Combined with the weak westerly climatological geostrophic flow in winter and hardly any climatological pressure gradients in summer, this can be seen as a composite of easterly flow that leads to fog in all of northern Switzerland, and southerly flows that just fill the valley between the Alps and the Jura with fog (Troxler and Wanner, 1991, Fig. 5a, c).

Composites of SLP for days with fog or mist in Potsdam (not shown) show patterns that are very similar to the ones for De Bilt (Fig. 6), but translated to the east by the distance between the stations (approx. $500 \mathrm{~km}$ ).

\subsection{Seasonal SLP patterns associated with low visibility}

In the previous section we established the daily circulation patterns associated with single low-visibility days. The next step is to investigate whether the seasonal mean pressure patterns of seasons with many fog or mist days are similar. In other words, we check whether the high-frequency daily signal can be averaged to a lower-frequency seasonal signal. This is not necessarily the case, as fog occurrences may depend on preconditioning that has different characteristics than the weather on the fog day itself. Only if the resulting seasonal mean circulation patterns are similar to the ones found in the composites can we use these as predictors for the number of low-visibility situations, and proceed towards the goal of attributing part of the downward trend to changes in circulation. If they disagree a more sophisticated

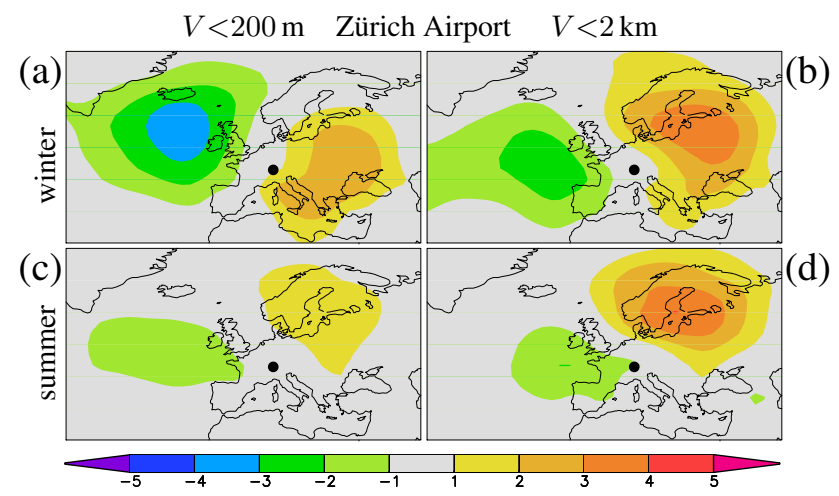

Fig. 7. As Fig. 6 but for Zürich Airport.

analysis taking both the preconditioning and the weather on the fog day itself into account will be needed.

As a measure of the effect of the seasonal mean circulation on low visibility we use the regression of the seasonal mean pressure on the number of dense fog or mist days. The maps show how much higher or lower than average the sea-level pressure is at each grid point when the number of dense fog or mist days at the station under consideration is one higher. A simple high-pass filter has been applied (year-on-year differences) to eliminate the influence of the trends to first order.

In Fig. 8 we show this regression map for the number of days at De Bilt with visibility less than $200 \mathrm{~m}$ and $2 \mathrm{~km}$. The winter regression patterns at De Bilt, Potsdam and mist at Zürich shown in Figs. 8 and 10 are similar to the composites of Fig. 6 with field correlations of $r=0.5$ to 0.9 , showing that a winter with many fog days has on average sea-level pressure pattern that is like the composite patterns associated with fog. For Zürich Airport dense fog the correspondence is much worse $(r \sim 0.1)$, with the flow more south-easterly than southerly.

In summer, the patterns completely disagree at De Bilt. Although fog and mist days there occur in a blocking situation, summers with the highest number of days have belownormal SLP in the Netherlands or to the west of it. This is an expression of the observation that in summer fog and mist only form when there is enough moisture, so they are most likely on a clear-sky day following a wet period. Figure 11 shows that the number of dense fog days in high summer (July-August) is higher when this part of the summer is dry, but lower when the preceding months have been dry. A wet spring or early summer leaves wet soils behind (Ferranti and Viterbo, 2006; Fischer et al., 2007; Vautard et al., 2007), leading to enough moisture, whereas summer fog itself is associated with dry weather. (Note that high summer circulation patterns are not very predictable from previous circulation patterns or sea surface conditions (e.g. van Oldenborgh et al., 2005).)

In Zürich Airport (Fig. 9) the summer regression patterns indicate that summers with a mainly south-easterly flow 


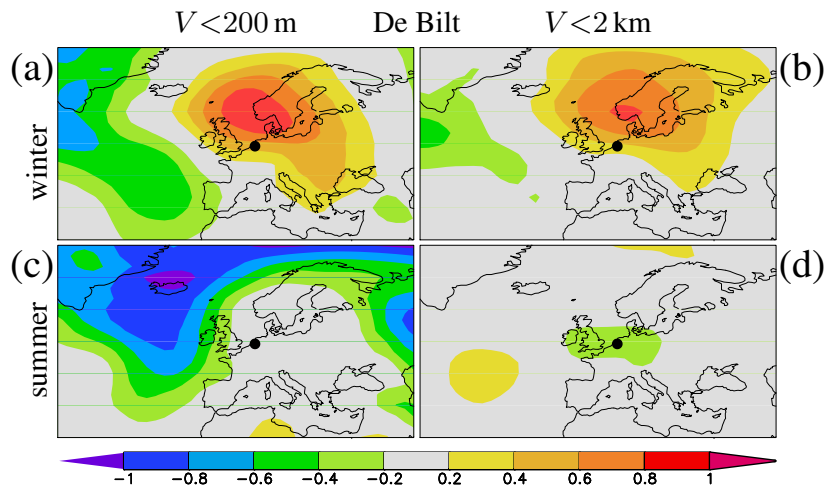

Fig. 8. Regression of the seasonal mean sea-level pressure on the number of days with low visibility in De Bilt [Pa month], the Netherlands (dot) in winter (a) and (c), and summer (b) and (d). In (a) and (c) the regression of days with dense fog (visibility less than $200 \mathrm{~m}$ ) is shown, in (b) and (d) the regression of days with visibility less than $2 \mathrm{~km}$.

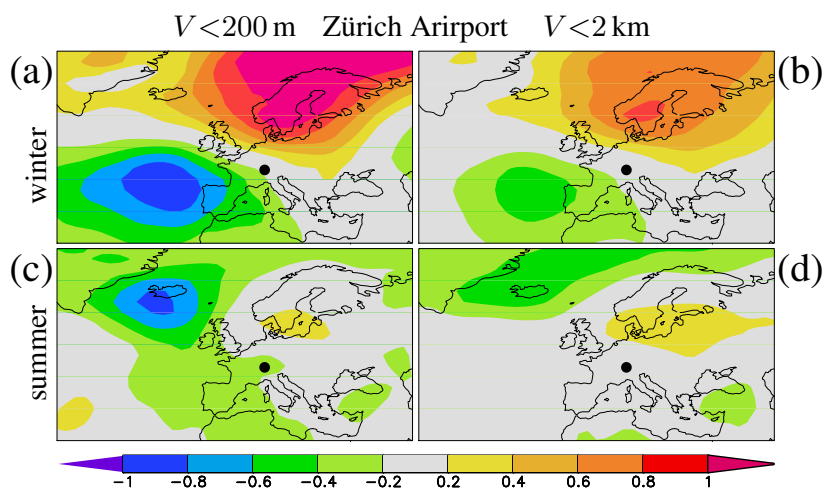

Fig. 9. As Fig. 8 but for Zürich Airport.

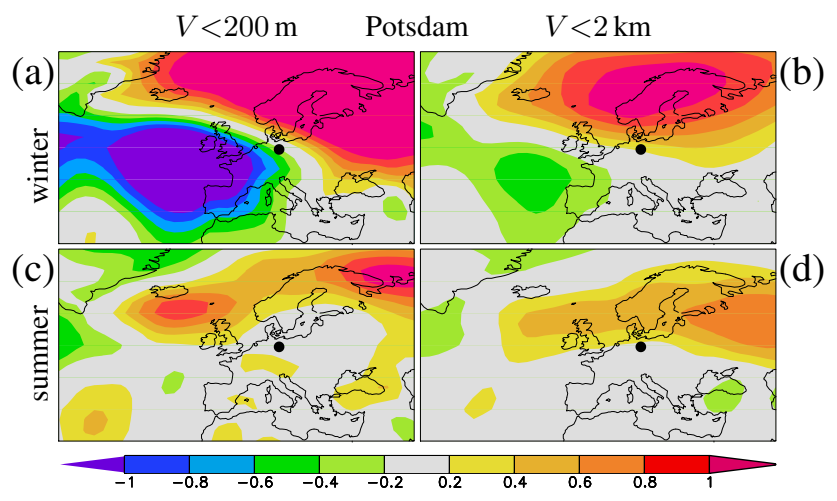

Fig. 10. As Fig. 8 but for Potsdam.

across Switzerland have the largest number of fog and mist days, in correspondence with the composite SLP on these days $(r \sim 0.4)$. Also at Potsdam there is better agreement between the daily composites and the seasonal means $(r=0.5$ to 0.6 ), although not as good as in winter. number of days with dense fog vs precipitation (De Bilt)

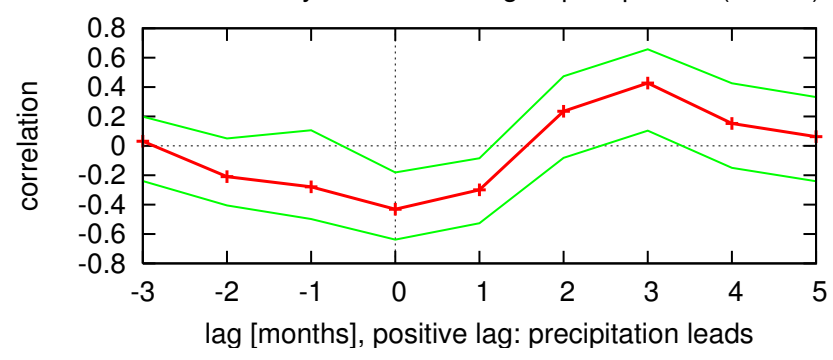

Fig. 11. Lag correlations of the number of days with minimum visibility less than $200 \mathrm{~m}$ at De Bilt in July-August with 2-month summed precipitation at the same station. Both series have been high-pass filtered by taking year-on-year differences. The green line indicates the $95 \%$ confidence interval, computed with a bootstrap method.

\section{Circulation influences on low visibility in Europe}

The patterns that are associated with foggy seasons are fairly local, and cannot be adequately described by the first few (rotated) EOFs of the large-scale flow, such as the NorthAtlantic Oscillation. The regressions of Figs. 8-10 usually consist of a dipole around the point at which the fog is observed. This suggests the use of local geostrophic wind at the surface (the first derivatives of the SLP field) and vorticity (the average second derivative) as indices for the large-scale circulation, as introduced in the context of temperature and precipitation sensitivities by van Ulden and van Oldenborgh (2006) and van Oldenborgh et al. (2009) and in the context of fog forecasting by Clark and Hopwood (2001). For instance at De Bilt we expect contributions from easterly geostrophic wind to cancel the background westerly flow, and from negative vorticity as a proxy for anticyclonic weather types. We therefore attempt to describe the anomalous number of fog days $N^{\prime}$ with a multiple linear regression on these local circulation indices, constructing the following very simple model (VSM):

$N^{\prime}(t)=A_{U} U^{\prime}(t)+A_{V} V^{\prime}(t)+B W^{\prime}(t)+\eta(t)$.

The geostrophic wind $U^{\prime}, V^{\prime}$ and vorticity anomalies $W^{\prime}$ are computed from the NCEP/NCAR reanalysis sea-level pressure (Kalnay et al., 1996) on a $20^{\circ}$ box around the station. The coefficients $A_{V}, A_{U}, B$ are fitted for winter and summer separately to minimise the noise residual $\eta$. Before applying the fitting procedure, a linear regression on time has been subtracted from all data $N^{\prime}, U^{\prime}, V^{\prime}, W^{\prime}$ in order to exclude the trend that we want to explain.

\subsection{Effects of geostrophic flows on low visibility}

We show the coefficients $A_{V}, A_{U}, B$ in Eq. (1) in Figs. 12-14 and the square root of the explained variance in Fig. 15.

In winters with a strong west circulation, the number of fog and mist days is generally lower than in winters with 

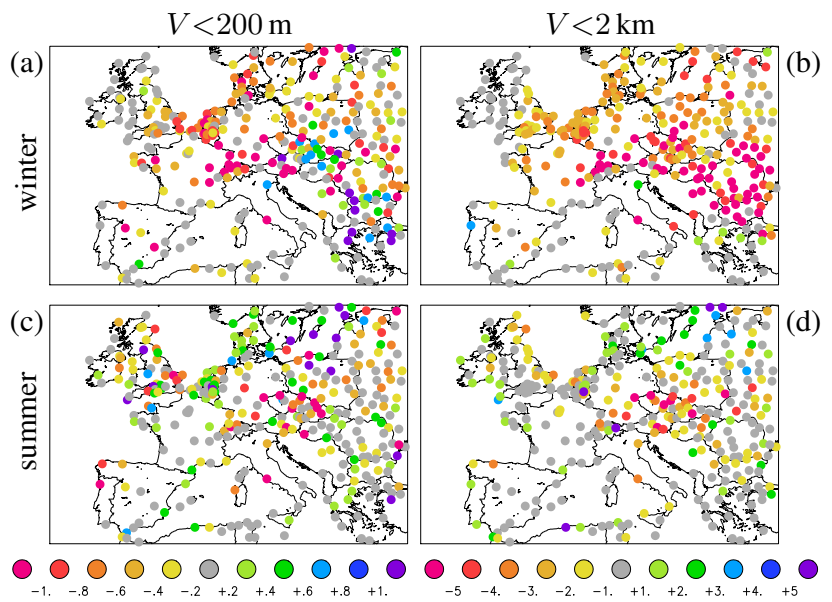

Fig. 12. The regression of the number of dense fog (a) and (c), and mist (b) and (d) days on zonal geostrophic wind $A_{U}\left[\mathrm{dy} \mathrm{m}^{-1} \mathrm{~s}\right]$, in winter (a) and (b), and summer (c) and (d).
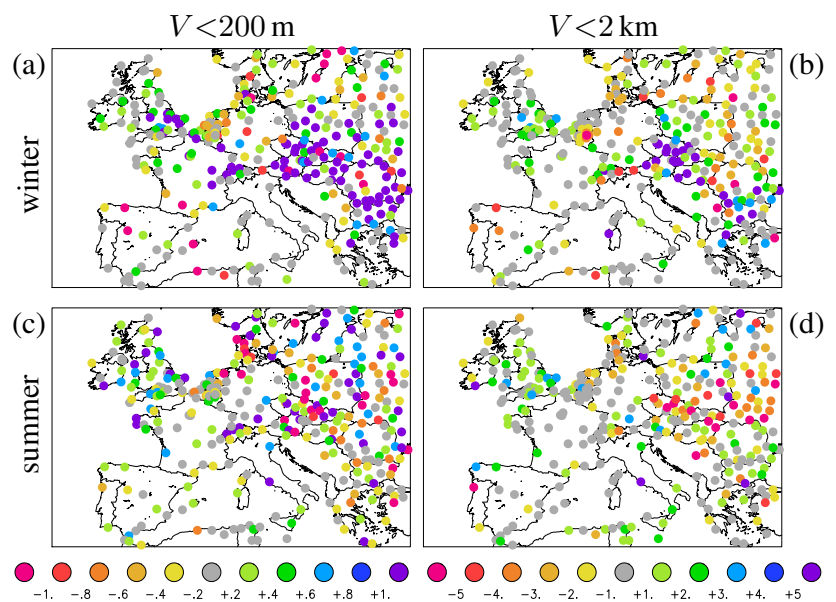

Fig. 13. As Fig. 12 but for meridional geostrophic wind $A_{V}$ $\left[\mathrm{dy} \mathrm{m}^{-1} \mathrm{~s}\right]$.
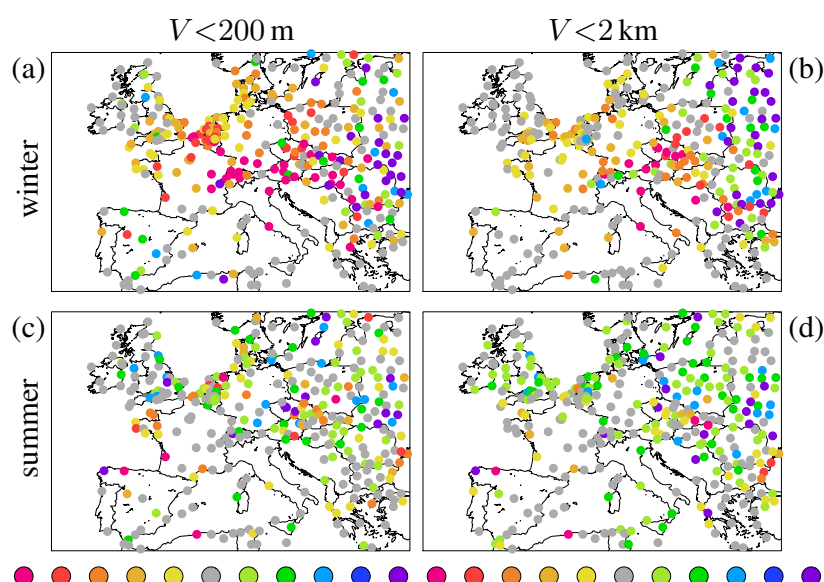

Fig. 14. As Fig. 12 but for geostrophic vorticity $B$ (arbitrary units).
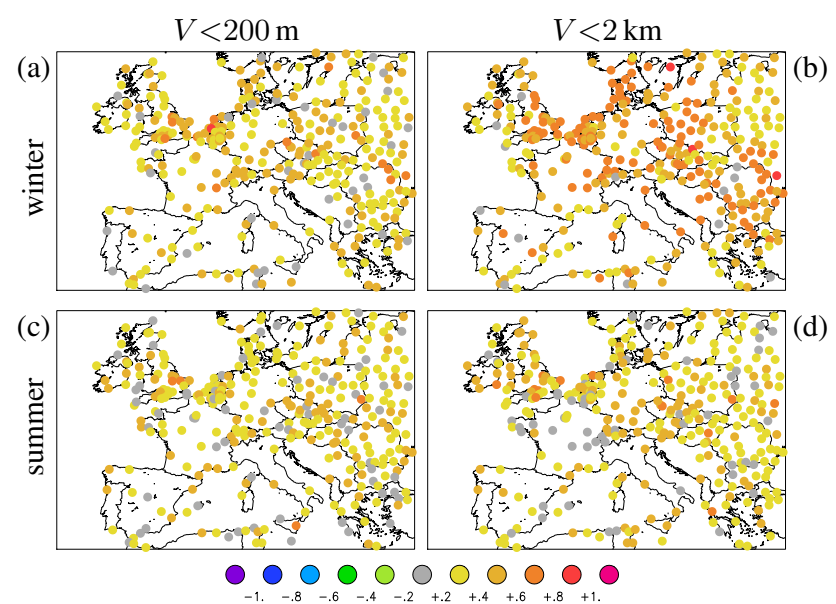

Fig. 15. The correlation of the VSM Eq. (1) without noise with the observed number of days of dense fog (a) and (c), and $2 \mathrm{~km}$ mist (b) and (d), in winter (a) and (c), and summer (b) and (d).

more blocking, in agreement with the situation at the three stations analysed in Sect. 5. This is not the case for dense fog in the Balkans. In this area, a stronger zonal geostrophic wind is associated with more dense fog, but less mist. Apparently different mechanisms play a role here for dense fog and mist.

In summer the effect of circulation is more dependent on local factors. An example is the east coast of Britain, where the regression is negative: easterly winds tend to advect sea fog to the land (Fig. 12). At the other side of the North Sea the sign is opposite.

North of the Alps and in eastern Europe, years with anomalously southerly winds have on average more fog and mist days.

Finally, the regression on vorticity (Fig. 14) shows that the opposition between summer and winter noted for De Bilt holds for a large part of Europe. In winter, a season with more negative vorticity (high pressure) gives rise to more fog days, due to more pollution and/or colder nights. In Russia and Ukraine, the relationship is the opposite. This effect is also noted by Ye (2009) and ascribed to the decreased availability of water vapour in high-pressure situations.

In contrast, summers with predominantly positive vorticity (low pressure) have more fog days, in agreement with the example of De Bilt presented in Sect. 5.

In summary, the large-scale circulation plays a role in fog and mist formation. The patterns associated with dense fog and $2 \mathrm{~km}$ mist are very similar except in the Balkans in winter. The VSM Eq. (1) explains about one quarter of the total variance of the detrended series in most of Europe in winter (Fig. 15 shows the square root of the explained variance). In fact, for one quarter of the stations $r>0.64$ for $2 \mathrm{~km}$ visibility, i.e., more than $40 \%$ of variability in the occurrence of $2 \mathrm{~km}$ mist there is explained by the large-scale circulation. In summer the explained variance is generally lower. 
In winter the circulation patterns affecting fog and mist have large scales. In most of Europe, more westerlies decrease the number of fog and mist days. Just north of the Alps and in eastern Europe, southerly flows also increase the number of fog days. High pressure (negative vorticity) increases fog and mist everywhere except the eastern edge of the study area.

In summer the patterns are more local. Positive vorticity (low pressure) is generally associated with fog in the seasonal mean, although individual fog days still are associated with a high-pressure situation. This implies that the seasonally averaged circulation alone does not give a good description of the occurrence of mist and fog in the summer season.

The regression analysis in this section does not show whether the influence of circulation is mainly due to differing concentrations of aerosols or directly by increasing the likelihood of favourable meteorological conditions.

\section{Trends in circulation and their effect on low visibility}

Over the last 50 years there have been significant trends in circulation in Europe, especially in late winter and early spring (see e.g. van Oldenborgh and van Ulden, 2003; Osborn, 2004; van Oldenborgh et al., 2009). The trends in January-March zonal geostrophic wind $U$ are shown in Fig. 16 for the periods 1948-2007 and 1976-2006. Increased air pressure over the Mediterranean and decreased pressure over Scandinavia have caused more westerly flows over the area north of the Alps. The pattern is very similar between the whole period of the reanalysis (1948-2007) and the period for which the European horizontal visibility data is available (1976-2006). Over the longer period the trend is highly significant. Combined with the reduction of fog and mist days in the same area in winters with westerly flows (Fig. 12), this implies that the change in circulation in January-March played a role in the reduction of low visibility there.

Over 1948-2009 there are no significant trends in the meridional geostrophic wind, although the sub-period 19762006 shows an increase in northerly flows over eastern Europe in late winter (not shown). The positive regression on meridional flows (Fig. 13) implies that this shift contributed to the observed reduction of fog and mist days over 19762006 in this area.

The NCEP/NCAR reanalysis also has a strong trend towards lower vorticity over the Alps. However, this trend is absent in the ERA40 reanalysis (Uppala et al., 2005), so it is not considered further here.

We can now find an estimate of the trend in the number of low visibility days due to circulation changes by multiplying the trends in geostrophic wind and vorticity with the regression on these indices:

$\frac{d N_{\mathrm{circ}}}{d t} \approx A_{U} \frac{d U}{d t}+A_{V} \frac{d V}{d t}+B \frac{d W}{d T}$

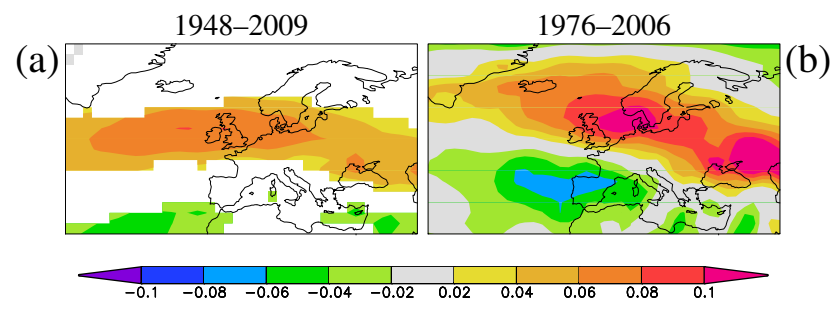

Fig. 16. Trends in January-March zonal geostrophic wind $U$ $\left[\mathrm{ms}^{-1} \mathrm{yr}^{-1}\right]$ over 1948-2009 (a) and 1976-2006 (b). In (a) only grid boxes with $p<0.1$ are shown.

This contribution to the trend in shown in Fig. 17. For comparison we show the contribution of increased westerlies in isolation in Fig. 18, i.e. retaining only the first term in Eqs. (1) and (2).

The shift towards more westerly flows in the second half of winter contributed to the observed trend towards fewer dense fog and mist days. However, the addition of meridional wind and vorticity in the analysis muddles the picture considerably, especially for dense fog. For instance, over the period 1976-2006 there has been a decrease in vorticity over much of Europe, counteracting the effect of the increase in zonal geostrophic wind. One sees that, especially for dense fog, the signal/noise ratio in just 30 years of observations starts to become a limiting factor.

Overall, the effects of shifts in large-scale circulation on the trend in dense fog and mist days have been much smaller than the trend itself. Even in the second half of winter, the contribution of the shift in circulation is at most 20\% (note the factor five different scale in Figs. 17 and 18 compared to Fig. 2). This implies that other factors have been more important in causing the large observed trends.

\section{Outlook}

Most, but not all, climate models project an increase in westerly flow over Europe in winter similar in pattern, but much smaller in amplitude, to the trend observed over the last 60 years (van Oldenborgh et al., 2009). This shift in circulation would lead to a decrease in the number of fog and mist days north of the Alps. For the Netherlands, the magnitude of the shift is taken to be between 0 and $1 \mathrm{~ms}^{-1}$ for a global mean temperature rise of $2 \mathrm{~K}$ (van den Hurk et al., 2007). This corresponds to a decrease of the number of fog and mist days due to circulation changes of $0 \%$ to $25 \%$, using the numbers of Fig. 12. If the dependence of low visibility on fog is primarily through aerosol concentrations rather than directly through the meteorological influence, the effect of a change in the weather statistics on low visibility will be smaller in the future than it is today. It is not possible to differentiate between direct meteorological influences and indirect ones 


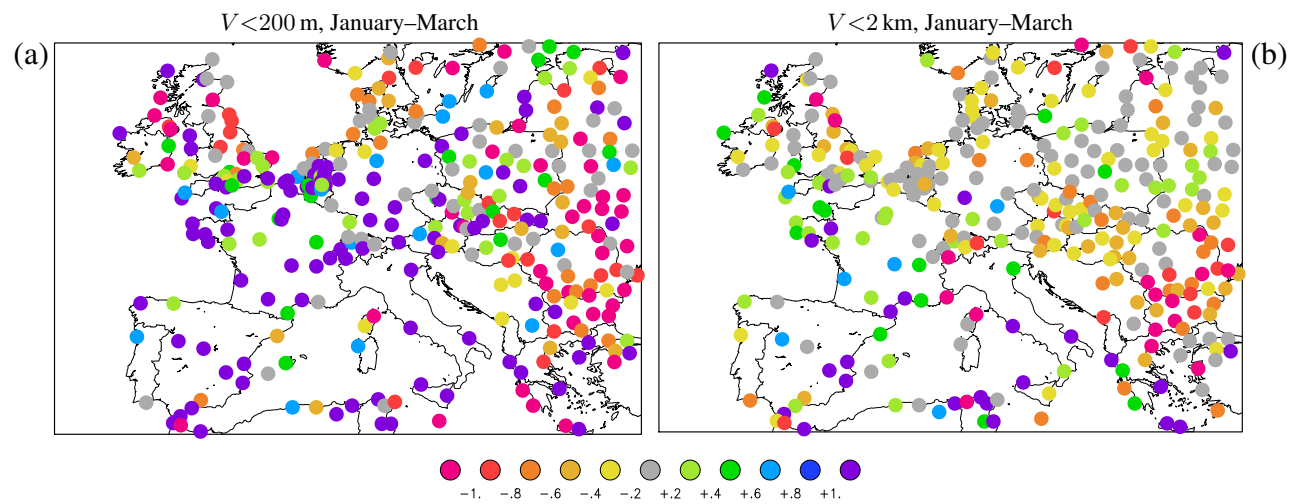

Fig. 17. Relative trend in visibility [\%/yr] due to circulation changes in January-March. (a) dense fog (200 m), (b) mist (2 km).

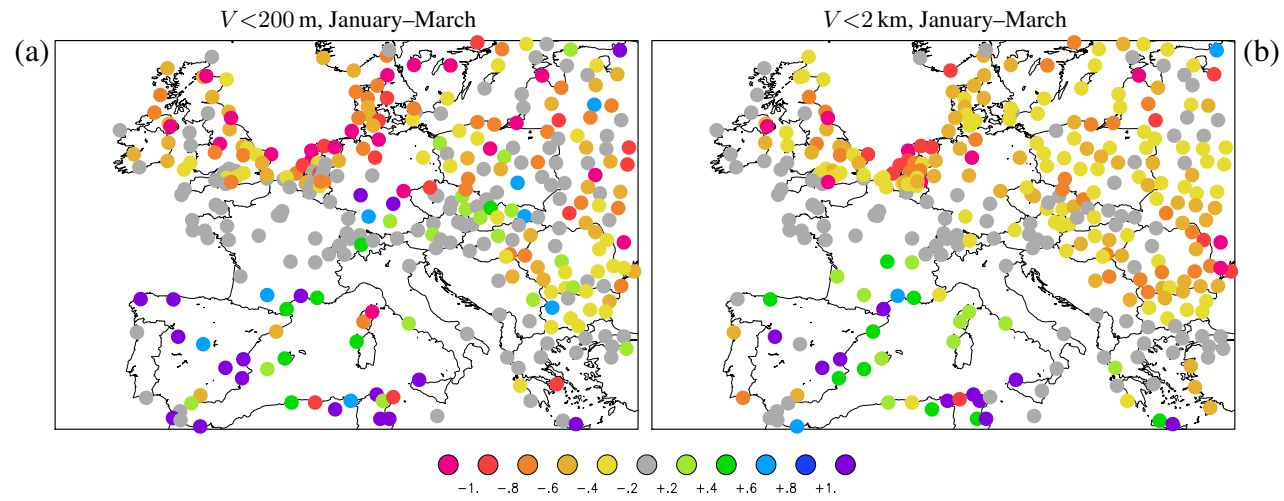

Fig. 18. As Fig. 17 but only taking zonal geostrophic wind $U$ into account.

through the aerosol concentrations for given emissions statistically based on the limited data we have available.

In high summer (July-August), fog tends to occur in dry spells after a rainy period weeks to months earlier. Most, but not all, climate models project a drying trend in Europe in summer (IPCC, 2007), decreasing the occurrence of summer fog further.

Probably a more important factor in the trend observed up to now has been the decrease in sulphur dioxide emissions leading to decreased concentrations of sulphate aerosols. The past evolution of aerosol emission has many uncertainties. Their fate in the future strongly depends on the technology and climate mitigation choices that will be made. However, at the European level, the legislation pressure on air quality makes it improbable that aerosol emission increase. The emission scenarios for the fifth IPCC Assessment Report project a further decrease in $\mathrm{SO}_{2}$ emissions in Europe. In 2050 emissions are assumed to be $90 \%$ lower than in 2009 in the RCP26 scenario (van Vuuren et al., 2007), more than $60 \%$ lower in the RCP45 scenario (Smith and Wigley, 2006; Wise et al., 2009) and 75\% lower in the RCP85 scenario (Riahi et al., 2007). All these reductions are fairly uniform in space. Although we have not been able to quantify the strength of the connection between aerosol emissions and fog, these steep reductions, if achieved, will reduce the number of fog days further.

The trend to more urban area in western Europe may also have contributed to the observed trend over the last 30 years. It is unlikely that this trend will be reversed over the next decades, so this factor will most likely not counteract the trends due to projected changes in atmospheric dynamics and aerosol emissions.

There are other local factors that may have affected fog that we have not considered in this analysis. The availability of moisture has changed due to the increase in built-up area and lower ground-water tables. The stability of the lower part of the atmosphere is obviously an important factor in fog formation. This stability may have changed, because of climate changes or as a result of changes in the ground-level environment, such as more heat generation. Finally, as suggested by a reviewer, the cooling on clear nights will decrease due to increased downwelling long-wave radiation, the primary mechanism of global warming. These effects have not yet been quantified and hence are not included in this first projection, but again are unlikely to reverse sign from the last 30 years. 
This outlook should be viewed as a first step based on a statistical analysis of a subset of the factors causing fog. Further progress depends on (regional) climate models resolving fog explicitly, with realistic land surface properties and temperature-dependent aerosol emissions, utilising the expertise that has already been developed for weather forecasting.

\section{Conclusions}

Based on four times daily observations of horizontal visibility over 1976-2006 we find significant decreases in the number of days with low visibility both for dense fog (visibility less than $200 \mathrm{~m}$ ) and mist (visibility less than $2 \mathrm{~km}$ ). In large parts of Europe these decreases correspond to a halving of the number of fog and mist days. The signal is coherent across countries and does not differ between airports and other stations. This indicates that changes in observing practices are not the main cause of the observed decline.

The decrease in number of fog and mist days is spatially and temporally correlated with the decrease in $\mathrm{SO}_{2}$ emissions for all ranges. The correlation is largest at $5 \mathrm{~km}$ visibility, but the correlations are also statistically significant for dense fog, in agreement with the micro-meteorological modelling studies discussed in Sect. 4. The spatial correlation between trends in fog and urbanisation is lower, but of the expected sign for all ranges studied.

The large-scale circulation affects fog in two ways: directly by influencing the local meteorological conditions that lead to fog, and indirectly by advection, concentration and removal of aerosols from the atmosphere. With the methods presented in this paper we can not distinguish between those effects.

Changes in large-scale circulation are correlated with the number of mist and fog days over most of Europe. In winter for $2 \mathrm{~km}$ the correlation coefficient of detrended data are around 0.6 except in areas with very little fog. In summer other factors are more important and the correlations are around 0.4. For dense fog the correlations are somewhat lower, but still sizeable.

There has been a trend towards more westerly circulation in January-March. This trend explains $20 \%-80 \%$ of the observed trends in mist in these months, and again somewhat less in dense fog. However, it is countered by the effects of other changes in circulation, so that the sum is much smaller, at most $20 \%$ of the observed trend. In other seasons the fraction of the trend explained by circulation changes is smaller still.

We conclude that for interannual variability the effects of circulation dominate, but for the trend other factors are more important. One factor that has been identified is the effect of the decreasing aerosol emissions over Europe. The trend to a larger fraction of urban land seems also to have played a role. Other factors such as moisture availability and heat generation at ground level have not been investigated. In the future, both the aerosol forcing and the circulation changes are projected to further decrease the occurrence of fog and mist in Europe.

Acknowledgements. We thank DWD and MeteoSwiss for providing the long-term visibility data at Potsdam and Zürich Airport. The RCP emission data were provided by FZ Jülich.

Edited by: J. Quaas

\section{References}

Bott, A.: On the influence of the physico-chemical properties of aerosols on the life cycle of radiation fogs, Bound. Lay. Meteor., 33, 1333-1346, doi:10.1007/BF00119960, 1991.

Clark, P. A. and Hopwood, W. P.: One-dimensional site-specific forecasting of radiation fog, Part I: Model formulation and idealised sensitivity studies, Meteorol. Appl., 8, 279-286, doi:10.1017/S1350482701003036, 2001.

Elias, T., Haeffelin, M., Drobinski, P., Gomes, L., Rangognio, J., Bergot, T., Chazette, P., Raut, J.-C., and Colomb, M.: Particulate contribution to extinction of visible radiation: Pollution, haze, and fog, Atmos. Res., 92, 443-454, doi:10.1016/j.atmosres.2009.01.006, 2009.

Ferranti, L. and Viterbo, P.: The European summer of 2003: sensitivity to soil moisture initial conditions, J. Climate, 19, 36593680, doi:10.1175/JCLI3810.1, 2006.

Fischer, E. M., Seneviratne, S. I., Lüthi, D., and Schär, C.: Contribution of land-atmosphere coupling to recent European summer heat waves, Geophys. Res. Lett., 34, L06707, doi:10.1029/2006GL029068, 2007.

von Glasow, R. and Bott, A.: Interaction of Radiation Fog with Tall Vegetation, Atmos. Environ., 33, 1333-1346, 1999.

van den Hurk, B. J. J. M., Klein Tank, A. M. G., Lenderink, G., van Ulden, A. P., van Oldenborgh, G. J., Katsman, C. A., van den Brink, H. W., Keller, F., Bessembinder, J. J. F., Burgers, G., Komen, G. J., Hazeleger, W., and Drijfhout, S. S.: New Climate Change Scenarios for the Netherlands, Water Sci. Technol., 56, 27-33, doi:10.2166/wst.2007.533, 2007.

Hurtt, G. C., Frolking, S., Fearon, M. G., Moore III, B., Shevliakova, E., Malyshev, S., Pacala, S. W., and Houghton, R. A.: The Underpinnings of Land-use History: Three Centuries of Global Gridded Land-Use Transitions, Wood Harvest Activity, and Resulting Secondary Lands, Glob. Change Biol., 12, 1208-1229, doi:10.1111/j.1365-2486.2006.01150.x, 2006.

IPCC: Climate Change 2007: The Physical Science Basis, Contribution of Working Group I to the Fourth Assessment Report of the Intergovernmental Panel on Climate Change (IPCC), edited by: Solomon, S., Qin, D., Manning, M., Chen, Z., Marquis, M., Averyt, K. B., Tignor, M., and Miller, H. L., Cambridge University Press, Cambridge, UK and New York, NY, 2007.

Kalnay, E., Kanamitsu, M., Kistler, R., Collins, W., Deaver, D., Gandin, L., Iredell, M., Saha, S., White, G., Woollen, J., Zhu, Y., Leetma, A., Reynolds, R., Chelliah, M., Ebisuzaki, W., Higgens, W., Janowiak, J., Mo, K. C., Ropelewski, C., Wang, J., and Jenne, R.: The NCEP/NCAR 40-year reanalysis project, B. Am. Meteorol. Soc., 77, 437-471, doi:10.1175/15200477(1996)077<0437:TNYRP>2.0.CO;2, 1996. 
Knip, K.: Grimmmist, NRC Handelsblad, 5 October, 2002.

Musk, L. F.: The fog hazard, in: Highway Meteorology, edited by: Perry, A. H. and Symons, L. J., Spon Press, London, UK, 91$130,1991$.

van Oldenborgh, G. J. and van Ulden, A. P.: On the relationship between global warming, local warming in the Netherlands and changes in circulation in the 20th century, Int. J. Climatol., 23, 1711-1724, doi:10.1002/joc.966, 2003.

van Oldenborgh, G. J., Balmaseda, M. A., Ferranti, L., Stockdale, T. N., and Anderson, D. L. T.: Evaluation of atmospheric fields from the ECMWF seasonal forecasts over a 15 year period, J. Climate, 18, 3250-3269, doi:10.1175/JCLI3421.1, corr. 51885198, 2005.

van Oldenborgh, G. J., Drijfhout, S., van Ulden, A., Haarsma, R., Sterl, A., Severijns, C., Hazeleger, W., and Dijkstra, H.: Western Europe is warming much faster than expected, Clim. Past, 5, 112, doi:10.5194/cp-5-1-2009, 2009.

Osborn, T. J.: Simulating the winter North Atlantic Oscillation: the roles of internal variability and greenhouse gas forcing, Clim. Dynam., 22, 605-623, doi:10.1007/s00382-004-0405-1, 2004.

Rangognio, J., Tulet, P., Bergot, T., Gomes, L., Thouron, O., and Leriche, M.: Influence of aerosols on the formation and development of radiation fog, Atmos. Chem. Phys. Discuss., 9, 1796318019, doi:10.5194/acpd-9-17963-2009, 2009.

Riahi, K., Grübler, A., and Nakicenovic, N.: Scenarios of long-term socio-economic and environmental development under climate stabilization, Technological Forecasting and Social Change, 74, 887-935, doi:10.1016/j.techfore.2006.05.026, 2007.

Sies, H.: A new parameter for sex education, Nature, 332, p. 495, 1988.

Smith, S. J. and Wigley, T. M. L.: Multi-Gas Forcing Stabilization with the MiniCAM, Energy J., 3, 373-391, 2006.

Sterl, A., van Oldenborgh, G. J., Hazeleger, W., and Burgers, G.: On the robustness of ENSO teleconnections, Clim. Dynam., 29, 469-485, doi:10.1007/s00382-007-0251-z, 2007.

Stern, D. I.: Reversal of the trend in global anthropogenic sulfur emissions, Global Environ. Chang., 16, 207-220, doi:10.1016/j.gloenvcha.2006.01.001, 2006.

Stern, R., Builtjes, P., Schaap, M., Timmermans, R., Vautard, R., Hodzic, A., Memmesheimer, M., Feldmann, H., Renner, E., Wolke, R., and Kerschbaumer, A.: A model inter-comparison study focusing on episodes with elevated $\mathrm{PM}_{10}$ concentrations, Atmos. Environ., 42, 4567-4588, doi:10.1016/j.atmosenv.2008.01.068, 2008.

Streets, D. G., Wu, Y., and Chin, M.: Two-decadal aerosol trends as a likely explanation of the global dimming/brightening transition, Geophys. Res. Lett., 33, L15806, doi:10.1029/2006GL026471, 2006.
Troxler, F.-X. and Wanner, H.: Nebelkarten der Schweiz, Geogr. Helvetica, 46, 21-31, 1991.

van Ulden, A. P. and van Oldenborgh, G. J.: Large-scale atmospheric circulation biases and changes in global climate model simulations and their importance for climate change in Central Europe, Atmos. Chem. Phys., 6, 863-881, doi:10.5194/acp-6863-2006, 2006.

Uppala, S. M., Kålberg, P. W., Simmons, A. J., Andrae, U., da Costa Bechtold, V., Fiorino, M., Gibson, J. K., Haseler, J., Hernandez, A., Kelly, G. A., Li, X., Onogi, K., Saarinen, S., Sokka, N., Allan, R. P., Anderson, E., Arpe, K., Balmaseda, M. A., Beljaars, A. C. M., van den Berg, L., Bidlot, J., Borman, N., Caires, S., Dethof, A., Dragosavac, M., Fisher, M., Fuentes, M., Hagemann, S., Hólm, E., Hoskins, B. J., Isaksen, L., Janssen, P. A. E. M., Jenne, R., McNally, A. P., Mahfouf, J.-F., Mocrette, J.-J., Rayner, N. A., Saunders, R. W., Simon, P., Sterl, A., Trenberth, K. E., Untch, A., Vasiljevic, D., Viterbo, P., and Woollen, J.: The ERA-40 re-analysis, Q. J. Roy. Meteorol. Soc., 130, 2961-3012, doi:10.1256/qj.04.176, 2005.

Vautard, R., Honoré, C., Beekmann, M., and Rouil, L.: Simulation of ozone during the August 2003 heat wave and emission control scenarios, Atmos. Environ., 39, 2957-2967, doi:10.1016/j.atmosenv.2005.01.039, 2005.

Vautard, R., Yiou, P., D'Andrea, F., de Noblet, N., Viovy, N., Cassou, C., Polcher, J., Ciais, P., Kageyama, M., and Fan, Y.: Summertime European heat and drought waves induced by wintertime Mediterranean rainfall deficit, Geophys. Res. Lett., 34, L07711, doi:10.1029/2006GL028001, 2007.

Vautard, R., Yiou, P., and van Oldenborgh, G. J.: Decline of fog, mist and haze in Europe over the past 30 years, Nat. Geosci., 2, 115-119, doi:10.1038/NGEO414, 2009.

van Vuuren, D., den Elzen, M., Lucas, P., Eickhout, B., Strengers, B., van Ruijven, B., Wonink, S., and van Houdt, R.: Stabilizing greenhouse gas concentrations at low levels: an assessment of reduction strategies and costs, Climatic Change, 81, 119-159, doi:10.1007/s/10584-006-9172-9, 2007.

Wild, M.: Global dimming and brightening: a review, J. Geophys. Res., 114, D00D16, doi:10.1029/2008JD011470, 2009.

Wise, M. A., Calvin, K. V., Thomson, A. M., Clarke, L. E., Bond-Lamberty, B., Sands, R. D., Smith, S. J., Janetos, A. C., and Edmonds, J. A.: Implications of Limiting $\mathrm{CO}_{2}$ Concentrations for Land Use and Energy, Science, 324, 1183-1186, doi:10.1126/science.1168475, 2009.

Ye, H.: The influence of air temperature and atmospheric circulation on winter fog frequency over Northern Eurasia, Int. J. Climatol., 29, 729-734, doi:10.1002/joc.1741, 2009. 